\title{
Transitional Skills Needed for the Hearing Impaired Students for the Transition from School to University in Jordan
}

\author{
Feryal Abdel- hadi Shanikat ${ }^{1, *}$ \\ ${ }^{1}$ The World Islamic Sciences \& Education University, Amman, Jordan \\ *Correspondence: The World Islamic Sciences \& Education University, Amman, Jordan
}

Received: February 26, 2017 Accepted: March 11, 2017 Published: March 29, 2017

doi:10.5296/ije.v9i1.11026 URL: https://doi.org/10.5296/ije.v9i1.11026

\begin{abstract}
The study aimed to identify the transitional skills necessary for the hearing impaired for the transition from school to university in Jordan, as well as to see the effect of variables such as gender, specialty, years of enrollment, non-transitional skills necessary for the transition from school to University in Jordan. The study sample consisted of (80) male and female students, from public and private universities in Jordan in Amman Governorate and Al Balqa, in order to collect the data, the researcher has built a study tool which consisted of 46 items distributed among three dimensions. Then the tool was applied to the sample.

The results showed that the academic skills ranked first with the highest mean of (3.22), followed by communication skills, and social skills with a mean of (2.85), the mean for the total score was (2.98). The results showed no statistically significant differences attributed to gender on the communication skills dimension, and results also showed a statistically significant differences due to the type of college variable and the difference was in favor of humanity colleges at all dimensions, the results also showed that there were no statistically significant differences on years of university enrollment variable at all dimensions and on the total score.
\end{abstract}

Keywords: Transitional Skills, Hearing Impaired Students, Transition 


\section{Introduction}

Hearing disabilities affect a number of functional capabilities of the individual patient including language and communication. Hearing impaired has been mentioned in many verses of the Koran.

Recent years have witnessed an increase in the number of hearing-impaired who are in regular schools and special schools of education, and this is not an indication of increasing disability, but an evidence of improved ways of disability detection, in addition to increasing the awareness of the family in the early detection and the progress in the level of services provided for the hearing impaired in all age groups. there are many definitions of audio disability, and most of these definitions are classified hearing disability to the concept hearing-impaired and hearing and hearing disability (Kuder, 2003).

there is a category of hearing disability which has loss of hearing before the acquisition of language, and loss of hearing after the acquisition of language, where hearing disability impose obstacles in the language and communicate among the hearing-impaired, and this requires the presence of distinguished services for the hearing impaired to overcome these obstacles and being able to adapt to society as much as possible. Where this kind of services is called support services, a non-educational services provided by specialists / professionals such as medical services, school health, and social or community, guidance, cognitive and rehabilitative / communicative to family, as well as rehabilitative and transitional services, where the final regulations for the Law individuals with disabilities (IDA) of the 1997 defined supportive services as mobility, development, debugging and other services aimed at helping the child to benefit from special education services.

The most important services provided for the hearing impaired :

1- Medical Services: where these services are provided by a doctor to determine the disability associated with the medical side, which is the medical history and physical examination.

2- Audio Services: these services are provided by audio specialist (Audiologist) where he diagnoses hearing and the measures the audio power.

3- Speech and language Pathology services: a specialist offers such services as speech and language and he evaluates the situation and determines the therapeutic program and provides rehabilitation services. (Heward, 2006).

4- Psychological services (Ps): a psychologist is providing psychological services where he assessed the situation and identified and appropriate treatment (Niche, 2001).

5- Counseling services: the counseling and guidance services are provided for the handicapped and hearing impaired and his family where the support services include the guidance of parents and their training and qualification of parents to actively participate in special educational program for the acoustically impaired (Smith, 2007).

6- School health services. 
7- $\quad$ Transport and mobility services, which includes transportation and travel to and from school, as well as other facilities in the community.

8- Transitional services: where transitional services refers to the role that acoustically disabled could contribute to in the community as an adult, which includes the areas of community participation and tool material income, health, and independent life, and the activities of leisure and recreation, and participation in secondary education programs (Khatib et al, 2007).

The preparation for the transition begins in the years of elementary and middle school begins where it based on the concepts of professional and encouraging acoustically disabled student to take advantage of all its capabilities and achieve a better level of responsibility (Sitlington and Clark, 2006). The aim of the transitional services is the contribution of the acoustically disabled at work and achieve a level of job satisfaction. There are educational and vocational programs that contribute to the rehabilitation and enroll them in jobs and higher education institutions.

\subsection{Problem of the study and its significance}

At the present time, the number of students with acoustic disabilities enrolled in higher education, and this shows the great interest of the categories of special education, and achieving the goal of special education, which is helping people with special needs to reach their full potential through educational services offered to them where its assumed that before reaching the Undergraduate the possession of hearing impaired the transitional post-secondary skills that help acoustically disabled to adapt to college. We have to recognize the transitional skills necessary to ensure the achievement of the desired objectives of the undergraduate application by the hearing-impaired, and not even being acoustically disabled for bad adjustment or are assessed in a wrong way and therefore it affects the academic and social motives and from here the interest in this subject came to be answering the following questions:

1- What are the transitional skills necessary for the transition from school to the university from the viewpoint of hearing impaired at public and private universities in Jordan?

2- Are there differences in the levels of transitional skills necessary for the acoustically disabled for the transition from school to the university from the viewpoint of hearing impaired at public and private universities due to gender?

3- Are there differences in the levels of transitional skills necessary for the acoustically disabled for the transition from school to the university from the viewpoint of hearing impaired at public and private universities due to the student's specialization?

4- $\quad$ Are there any differences in the levels of transitional skills necessary for the acoustically disabled for the transition from school to the university from the viewpoint of hearing impaired at public and private universities due to enrolling years in the 
university?

\subsection{Theoretical and practical importance of the study}

- Provide deaf students with the necessary skills at the secondary level in order to adapt to college life.

- To achieve compatibility and integration between the positive deaf and listeners.

- Provide the faculty at universities with the necessary information about the capabilities and skills of deaf students at Jordanian universities.

- To help students achieve academic and social success at the university.

\subsection{Objectives of the study}

1. Identify the process skills necessary for successful transmission of hearing-impaired from the school to the university stage.

2. Identify the impact of these variables, gender, years of enrollment, specialty.

3. Build a tool to measure the necessary skills to navigate the transition from school to university.

\subsection{Operational definitions}

Acoustically Disabled: a person who cannot rely on the sense of hearing to learn the language, or take advantage of education programs offered to the hearers, and he needs the teaching methods that compensate for the sense of hearing.

It is defined procedurally: university student with a disability to audio prevent him of learning and adapting to university life, and needs for a number of skills to adapt to college life.

Transitional skills: is the skill that enables acoustically disabled to contribute to society, and management of material income, and health. It is also the occupancy of leisure time and the recreation and participation in secondary education programs. It is defined procedurally: mainly achieved on the scale which was prepared by the researcher to measure the necessary skills to navigate the transition from school to university.

\subsection{Determinants of the study}

- The study is limited to the deaf students in the Jordanian public university.

- limited to deaf students and do not include the hearing impaired.

- Limited to deaf students aged (19-24 years).

\section{Literature Review}

\subsection{Theoretical Framework}

Several definitions for the hearing Impairment emerged because of the multiplicity of views 
on the subject of the hearing impaired, the most prominent of these definitions of medical definitions, where it defined the acoustically disabled that the individual who was injured auditory and organ damage and malfunction Organic prevent him from using it in public life as normal like any other ordinary people, and that means the failures or damage may hit the outer ear or middle or internal, this course may not include all the ear parts, but part or parts of them. as a matter of educational defined the acoustically disabled as a person who cannot rely on the sense of hearing to learn the language, or take advantage of different educational programs offered to the hearers, and he needs the teaching methods that compensate for the sense of hearing. As hard of hearing is that person who is suffering from loss of hearing ability may be able to compensate hearing aids, high sound intensity, and can learn the same way they learn their individual listeners after the use of assistive audio (Yusuf, Derbas, 2007).

\subsubsection{Classification of hearing disability}

Classification of hearing disability varies depending on the standard upon which the rating, there are three basic criteria in the classification of hearing disability, namely- :

1- Classification depending on the age of the disability occurred where is the age at which hearing disability of important variables in determining occurred resulting from the effects of hearing disability, because of its importance in determining the child's acquisition of language necessary expertise in the field of learning to communicate, and is divided according to this standard to:

\section{a. Pre lingual Deafness}

This type is also called congenital deafness, refers to cases of epilepsy that occurs at birth or at an earlier stage on the evolution of language and speech in children, experts have disagreed about the age that separates pre lingual deafness and post lingual deafness, some of them sees it 18 months, while others see to 3 years of age is the age interval, and these usually are not able to use speech, called the term (deaf, dumb).

b. Post lingual Deafness: and it refers to cases of epilepsy that occurs after the child has acquired speech and language skills, and they are called the term deaf only.

\section{2- Classification depending on the site of injury}

The this category to determine the site of infection in the auditory system, both ear external and internal, and causing Hearing Impairment, according to this standard it is divided to: -

\section{a. Conductive Hearing Loss}

It produces from all the problems that plague external or middle ear, so as to prevent the arrival of the sound wave naturally to the inner ear, has been caused by a blockage in the external auditory canal; because of the accumulation of wax in the ear, or the entry of foreign objects, or puncture the eardrum and others. this type of loss can be corrected medically or surgically, or by using the audio amplifiers, and symptoms of this type of auditory loss is a pain in the ear, and out secretions, and tumor outer ear, feeling the pressure in the ear, and the 
degree of auditory loss of less than $70 \mathrm{~dB}$.

\section{b. Sensor neural Hearing Loss}

It is also called the term (deafness nerve), caused by damage to the inner ear or the auditory nerve, although the waves reach the inner ear, but to convert them into electrical charges inside the enclosure may not be properly, or to be a bug in the auditory nerve is not are transported to the brain fully, audio and loss of sensory nerve affects not only the ability to hear sounds, but to understand them as well; because the sounds audible exposed to distortion prevents understand, and in most cases the patient suffers from the inability to hear high tones, and classifies the patient in this case he speaks loudly, and the weakness in distinguishing letters and speech, the most common of this disorder and the causes are aging, and inflammation of the inner ear, the noise exposure and head injuries, and tumor auditory nerve, and taking certain medications, and birth defects . neural hearing $\mathrm{N}$ to deal with it medically or surgically usually, but this category may benefit from the earphones, but a low degree, the degree of auditory loss higher than $70 \mathrm{~dB}$.

\subsection{Previous Studies}

Many researchers conducted studies in the field of hearing impaired; the researcher reviewed some of these studies:

Masaadeh (1990) conducted a study entitled disabled students' problems in Jordanian universities where the study aimed to identify these problems and their relationship to gender and academic level and the type of disability and place of residence, type of college, where study sample consisted of 55 disabled students disabled from various Jordanian universities, where results showed that the biggest problems faced by the disabled in Jordanian universities are problems related to the side of services, then the future side, followed by the health aspect, and then the social side and the academic side, the economic aspect and the psychological aspect, the results showed no statistically significant differences due to gender, and academic level and type of disability .

A study conducted MarsChark (2005) entitled access to education beyond high school through the translation of sign language, where the goal of this study is to identify the effectiveness of translation in sign language for the deaf in the classroom, and the sample of the study consisted of 150 persons, including (127) volunteering students from Roster Institute of technology for the Deaf, among these volunteers (22) of listeners students, including 9 males and the rest females, (105) deaf students, including 60 males and the rest females as well (23) sign language interpreters. The researcher put translators in the course of lectures for deaf students at the university level, and then displays all students to test to find out how to take advantage of the content and understanding it, results pointed to a contradiction regarding the importance of preferring of students to translate, and it also pointed out that the deaf students acquire less Information than their listeners colleagues, they are also weak in school readiness, quality of education and the quality of the translation.

Albertini \& Ashley Study (2005) entitled evaluate the writing of university deaf students, where the objective of the study to identify the clerical level of deaf students who attend the 


\section{Macrothink}

International Journal of Education

ISSN 1948-5476

2017, Vol. 9, No. 1

National Technical Institute for the Deaf, where the researcher designed four levels of writing, ranging from easiest to hardest and formed the sample of 236 students who wants to go to university.

A study of (Walter, Bochner, 2005) aimed to disclose alternative methods for assessing the readiness of students with hearing disabilities to cope with learning the English language in the post-secondary level where the study sample consisted of (905) of the students with hearing disabilities who responded on the reading test ( ACT) and test integration NTTD, the results showed the presence of deficiencies in the evaluation standards used, where it does not take account of acoustically disabled students properties.

The study of (Gale, 2006) in the United States aimed to identify the learning needs of students with audio disabilities of quality standards, where the study sample consisted of 56 male and female students with hearing disabilities in one of New York Universities, the researcher used a questionnaire about the services provided, where the results showed a lack of perception by presenters on the acoustic disabled properties. And also supporting services do not depend on specific criteria, aged (19-49 years), and most of them (17-22 years) results indicated that teachers of writing who are trained to conduct assessment locally developed produced certified guest writing and the students' level in writing is in evolutionary levels.

Lukomski (2007) study aimed to recognize the differences in the look of deaf students and listeners to their psychological and social agreement after they move to the university stage where the researcher applying Standard life difficulties in adolescence scales where it was found that the deaf classified themselves as facing difficulties in social life more than listeners, they also have the least capacity to deal with the problems, and the results showed that deaf females are to have more anxiety from the listeners.

\section{Design and Methodology}

\subsection{The Population of the Study and its Sample}

The population of the study consisted of acoustically disabled students enrolled in Jordanian government and private universities in all governorates of the Kingdom estimated at 120, based on the statistics of the Supreme Council for the disabled in 2013, it has been possible to reach (80) students of them. Table 1 shows the distribution of individuals according to the study variables. 


\section{Macrothink}

Table 1. The Distribution of the Study Sample According to Variables Duplicates and Ratios According to Study Variables

\begin{tabular}{llll}
\hline \multirow{3}{*}{ Gender } & Categories & Repetition & Ratio \\
& Male & 31 & 38.8 \\
Academic year & Female & 49 & 61.3 \\
& First & 30 & 37.5 \\
& Second & 22 & 27.5 \\
& Third & 17 & 21.3 \\
& Fourth & 11 & 13.8 \\
Specialization & Hummanity colleges & 70 & 87.5 \\
& Scientific colleges & 10 & 12.5 \\
& Total & 80 & 100.0 \\
\hline
\end{tabular}

\subsection{The Study Tool}

The study tool was built with the help of:

- The theoretical literature on the topic, such as the following references:

- Learning Needs of Deaf in the Institutions American Annuals of Deaf Students

- Arab and foreign studies, such as disabled students at Jordanian universities' problems, Unpublished MA Thesis, College of Education, Yarmouk University, Jordan.

- Some measures, such as (the Jordanian version for the scale of the levels of support.

- Some individuals working with the hearing impaired, such as sign language interpreters for the hearing-impaired students in universities affiliates.

- An interview with the hearing-impaired and ask them a question about the necessary skills for the acoustically disabled to move to the university.

- An interview with the faculty has been conducted, and they were asked about the skills necessary for the acoustically disabled enrolled in universities.

- The skills that were mentioned were distributed among the above three dimensions, a first dimension of communication, the second dimension the social skills, the third dimension the academic skills.

- Where the scale is in the initial image consists of (46) items, where the first dimension which is the communication consists of (13) items, the second dimension consists of (16) items, the third dimension consists of (17) items. Where the answer falls in four levels, which is needs greatly, needs medium, Low need, no need, the acoustically disabled choose the answer that apply to him. After deleting and modifying some of the paragraphs, the scale consists of 46 items, where the first dimension of communication (13) items, the second dimension regards social skills consists of (16) items, the third dimension regards academic skills consists of (15) items. 


\section{MInstitute Macrothink}

\subsection{Validity and Reliability of the Tool}

\subsubsection{Content Validity}

Content validity was extracted by displaying the scale on (10) of the arbitrators of the faculty members in Jordanian universities (university of Jordan, Al Balqa Applied university, and World Islamic sciences university) and translators of sign language accompanying the hearing impaired students at universities, they were asked to assess the appropriateness of the items of what it was developed to measure, and how clarity the formulation of items after revising the objectives of the scale, and then propose appropriate amendments, then standard agreement of eight arbitrators were adopted to show the validity of item and suitability to remain within the scale, and the agreement of the two arbitrators on the lack of clarity to amend it. Based on the views of the arbitrators' specialists, some of the items have been amended in terms of drafting and separation of some items which included two items in one item to increase the clarity of items, and no item has been added, but some inappropriate items have been deleted to fit the study sample.

\subsubsection{Construct Validity}

To extract the semantics of construct validity of the scale, correlation coefficient of the scale items with the total score were extracted in the exploratory sample from outside the study sample consisted of 30 hearing impaired students, where the scale's items were analyzed and decimation coefficient for each item was calculated, since the discrimination factor here is a sign of validity for each item in the image correlation coefficient between each item and the total score on the one hand, and between each item and the association axis that belongs to it, and between each axis and the total score on the other hand, the correlation coefficient between the items and the tool as a whole ranged between (0.31-0.78), and with the axis (0.37-0.90) and table 2 below shows that.

Table 2. Correlation Coefficients between the Items and the Total Score and the Axis It Belongs to

\begin{tabular}{|c|c|c|c|c|c|c|c|c|}
\hline $\begin{array}{l}\text { Item } \\
\text { No. }\end{array}$ & $\begin{array}{l}\text { The } \\
\text { correlation } \\
\text { coefficient }\end{array}$ & $\begin{array}{l}\text { The } \\
\text { correlation } \\
\text { coefficient }\end{array}$ & $\begin{array}{l}\text { Item } \\
\text { No. }\end{array}$ & $\begin{array}{l}\text { The } \\
\text { correlation } \\
\text { coefficient }\end{array}$ & $\begin{array}{l}\text { The } \\
\text { correlation } \\
\text { coefficient }\end{array}$ & $\begin{array}{l}\text { Item } \\
\text { No. }\end{array}$ & $\begin{array}{l}\text { The } \\
\text { correlation } \\
\text { coefficient }\end{array}$ & $\begin{array}{l}\text { The } \\
\text { correlation } \\
\text { coefficient }\end{array}$ \\
\hline & $\begin{array}{l}\text { With the } \\
\text { Axis }\end{array}$ & $\begin{array}{l}\text { With the } \\
\text { tool }\end{array}$ & & $\begin{array}{l}\text { With the } \\
\text { Axis }\end{array}$ & $\begin{array}{l}\text { With the } \\
\text { tool }\end{array}$ & & $\begin{array}{l}\text { With the } \\
\text { Axis }\end{array}$ & $\begin{array}{l}\text { With the } \\
\text { tool }\end{array}$ \\
\hline 1 & .61 & .69 & 16 & .58 & .53 & 31 & .74 & .63 \\
\hline 2 & .75 & .35 & 17 & .66 & .50 & 32 & .68 & .51 \\
\hline 3 & .74 & .38 & 18 & .73 & .58 & 33 & .83 & .77 \\
\hline 4 & .38 & .34 & 19 & .37 & .43 & 34 & .82 & .76 \\
\hline 5 & .70 & .49 & 20 & .64 & .51 & 35 & .72 & .61 \\
\hline 6 & .82 & .59 & 21 & .50 & .35 & 36 & .88 & .78 \\
\hline 7 & .58 & .34 & 22 & .47 & .31 & 37 & .90 & .76 \\
\hline 8 & .74 & .50 & 23 & .66 & .44 & 38 & .89 & .67 \\
\hline 9 & .70 & .58 & 24 & .60 & .51 & 39 & .85 & .66 \\
\hline 10 & .61 & .33 & 25 & .44 & .39 & 40 & .82 & .65 \\
\hline 11 & .77 & .55 & 26 & .65 & .65 & 41 & .85 & .75 \\
\hline 12 & .40 & .37 & 27 & .77 & .69 & 42 & .87 & .75 \\
\hline 13 & .74 & .61 & 28 & .76 & .68 & 43 & .67 & .55 \\
\hline 14 & .56 & .40 & 29 & .54 & .64 & 44 & .79 & .58 \\
\hline 15 & .67 & .64 & 30 & .62 & .47 & & & \\
\hline
\end{tabular}


It is worth mentioning that all correlation coefficients were of acceptable and statistically significant degree, so none of these paragraphs is deleted.

Table 3. Correlation Coefficients between the Axes and Total Score

\begin{tabular}{lllll}
\hline & $\begin{array}{l}\text { Communication } \\
\text { skills }\end{array}$ & $\begin{array}{l}\text { Social } \\
\text { skills }\end{array}$ & $\begin{array}{l}\text { Academic } \\
\text { skills }\end{array}$ & Total score \\
\hline Communication skills & 1 & & & \\
Social skills & $.501^{* *}$ & 1 & & \\
Academic skills & $.236^{*}$ & $.596^{* *}$ & 1 & 1 \\
Total score & $.665^{* *}$ & $.870^{* *}$ & $.832^{* *}$ & 1 \\
\hline
\end{tabular}

* Statistically significant at the significance level (0.05).

** Statistically significant at the significance level (0.01)

Reliability of study tool: To ensure the reliability of the tool, the internal consistency was calculated on an exploratory sample from outside the study sample of which consists of(40) students using Cronbach's alpha formula, and Table 4 below shows these transactions and it is considered the appropriate ratios for the purposes of this study.

Table 4. Internal Consistency Coefficient Cronbach's Alpha

\begin{tabular}{ll}
\hline Dimensions & Internal consistency \\
\hline Communication skills & 0.88 \\
Social skills & 0.87 \\
Academic skills & 0.91 \\
\hline Total score & 0.94 \\
\hline
\end{tabular}

\subsection{Procedures of the Study}

The scale in its final version has been applied to acoustically disabled students enrolled in Jordanian universities by reading paragraphs by the translator and interpreting it to the group that could be accessed from various public and private universities (the World International Islamic university, the university of Jordan, Amman Arab university), where the scale items were read and interpret by accompanying language Signal interpreter for students in these universities, then the disabled picks acoustically the answer that applies to him, since the answer ranging in four levels, the application of the scale has continued for a month, after two weeks it was re-applied on (40) students to ensure the reliability of the scale.

\subsection{Design of the Study}

The researcher used means and standard deviations and "T" test to demonstrate the effect of variables. 


\section{Results of the Study}

The first question: "What are the necessary transitional skills for the transition from school to the university from the viewpoint of hearing impaired at public and private universities in Jordan?

To answer this question means and standard deviations of the transition skills necessary for the hearing impaired for the transition from school to the university were extracted, and the level has been determined by determining the means of 1-2 low, 2.1 -3 medium, and 3.1-4 high, the table No. (5) Illustrates this

Table 5. Means, Standard Deviations of the Transition Skills Necessary for the Hearing Impaired to Transfer from School to University in Descending Order According to Means

\begin{tabular}{lllll}
\hline Rank & Axis & Mean & Standard deviation & Level \\
\hline 3 & Academic skills & 3.22 & .79 & High \\
1 & Communication skills & 2.85 & .61 & Medium \\
2 & Socisl skills & 2.85 & .55 & Medium \\
& Total score & 2.98 & .52 & Medium \\
\hline
\end{tabular}

Table (5) shows that the academic skills ranked first with the highest mean reached (3.22), followed in second place each of the communication skills, and social skills with a mean of (2.85), and the mean of the total score reached (2.98).

Means and standard deviations of the study sample estimates of the paragraphs of each skill separately were calculated, and were as follows:

\section{First, communication skills}

Table 6. Means and standard deviations of the communication skills items in descending order according to the means

\begin{tabular}{|c|c|c|c|c|c|}
\hline Rank & $\mathrm{N}$ & Items & Mean & $\begin{array}{l}\text { Standard } \\
\text { deviation }\end{array}$ & Level \\
\hline 1 & 1 & Training on scientific sign language & 3.60 & .92 & High \\
\hline 2 & 3 & Training on the total means of communication & 3.04 & .95 & High \\
\hline 3 & 8 & Training on the skill of communicating with teachers & 3.03 & .93 & Medium \\
\hline 4 & 6 & $\begin{array}{l}\text { Training on the skill of effective communication with } \\
\text { colleagues }\end{array}$ & 2.85 & 1.01 & Medium \\
\hline 5 & 2 & Training to understand gestures and hints & 2.84 & .93 & Medium \\
\hline 5 & 4 & Mastering the skill of speech training & 2.84 & .96 & Medium \\
\hline 7 & 11 & Training on the skill to express gestures & 2.79 & .87 & Medium \\
\hline 7 & 12 & Trained to recognize hints by listeners & 2.79 & .90 & Medium \\
\hline 9 & 7 & $\begin{array}{l}\text { Training on the skill of communicating with different } \\
\text { nationalities }\end{array}$ & 2.73 & .93 & Medium \\
\hline 10 & 5 & Training on the skill of follow-up the university advertisements & 2.70 & .93 & Medium \\
\hline 10 & 10 & Training to communicate with the opposite gender & 2.70 & .96 & Medium \\
\hline 12 & 9 & $\begin{array}{l}\text { Training on communication skill with professional staff in the } \\
\text { university }\end{array}$ & 2.69 & .85 & Medium \\
\hline \multirow[t]{2}{*}{13} & 13 & Training on the visual communication with listeners & 2.50 & .94 & Medium \\
\hline & & Communication skills & 2.85 & 61 & Medium \\
\hline
\end{tabular}




\section{Ml Macrothink}

Table (6) shows that the means have ranged from (2.50-3.60), where the item No. 1, which was, "Training on scientific sign language" in the first place and a mean of (3.60), while paragraph (13) which is " training on the visual communication with listeners," came in the last rank and an arithmetic mean was (2.50). The mean of communication skills as a whole reached (2.85).

\section{Second: social skills}

Table 7. Means and standard deviations of the items of social skills in descending order according to means

\begin{tabular}{|c|c|c|c|c|c|}
\hline Rank & $\mathrm{N}$ & Items & Mean & $\begin{array}{l}\text { Standard } \\
\text { deviation }\end{array}$ & Level \\
\hline 1 & 16 & $\begin{array}{l}\text { Knowledge of the duties of a sign language } \\
\text { interpreter }\end{array}$ & 3.18 & 1.06 & High \\
\hline 2 & 8 & Training on the skill of defending their rights & 3.11 & .83 & High \\
\hline 3 & 1 & $\begin{array}{l}\text { Training to communicate and get to know the } \\
\text { listeners }\end{array}$ & 2.99 & .95 & Medium \\
\hline 4 & 11 & $\begin{array}{l}\text { Training on the skill of the participation with } \\
\text { colleagues in the university duties }\end{array}$ & 2.93 & .67 & Medium \\
\hline 4 & 13 & $\begin{array}{l}\text { Training on the skill of acceptance and adapt to } \\
\text { society of listeners }\end{array}$ & 2.93 & .92 & Medium \\
\hline 6 & 3 & $\begin{array}{l}\text { To practice the skill of participating in extracurricular } \\
\text { activities }\end{array}$ & 2.92 & .94 & Medium \\
\hline 7 & 12 & Trained to accept the views of others & 2.91 & .86 & Medium \\
\hline 8 & 9 & $\begin{array}{l}\text { To practice the skill of solving social problems he } \\
\text { faced }\end{array}$ & 2.90 & .76 & Medium \\
\hline 9 & 6 & $\begin{array}{l}\text { Training on the skill to borrow references and } \\
\text { scientific traceable }\end{array}$ & 2.89 & 1.09 & Medium \\
\hline 10 & 10 & Training on thinking skills & 2.86 & .84 & Medium \\
\hline 11 & 5 & Training on the skill to participate in group activities & 2.83 & .82 & Medium \\
\hline 12 & 4 & $\begin{array}{l}\text { Training on the skill of the participation with normal } \\
\text { colleagues in their special occasions }\end{array}$ & 2.76 & .83 & Medium \\
\hline 13 & 14 & Training on the skill of joining the university club & 2.71 & 1.03 & Medium \\
\hline 14 & 15 & Training on the skill to identify the university teacher & 2.67 & 1.00 & Medium \\
\hline 15 & 2 & $\begin{array}{l}\text { Training on the skill to express different emotions } \\
\text { and feelings }\end{array}$ & 2.60 & .98 & Medium \\
\hline \multirow[t]{2}{*}{16} & 7 & $\begin{array}{l}\text { Training on the skill of the purchase from the } \\
\text { cafeteria }\end{array}$ & 2.42 & .96 & Medium \\
\hline & & Social skills & 2.85 & .55 & Medium \\
\hline
\end{tabular}

Table (7) shows that the means have ranged from (2.42-3.18), where item No. 16, which is "know the duties of a sign language interpreter" came the first place and an arithmetic mean was (3.18), while item (7) which is "train on the skill to purchase from the cafeteria," came at the last rank and an arithmetic mean was (2.42). The mean of social skills as a whole reached (2.85).

\section{Third: Academic skills}


Table 8. Means and standard deviations of the vertebrae academic skills in descending order according to means

\begin{tabular}{llllll}
\hline Rank & $\mathrm{N}$ & Items & Mean & $\begin{array}{l}\text { Standard } \\
\text { deviation }\end{array}$ & Level \\
\hline 1 & 1 & To practice the skill of reading & 3.56 & .61 & High \\
2 & 4 & To practice the skill of using computer & 3.40 & .99 & High \\
3 & 2 & Training on writing skills & 3.33 & 1.09 & $\begin{array}{l}\text { High } \\
3\end{array}$ \\
14 & The skill of reading in English & 3.33 & .90 & High \\
5 & 3 & To practice the skill of verbal and performing tests & 3.28 & .93 & High \\
5 & 5 & To practice the skill of using the Internet & 3.28 & .98 & High \\
7 & 6 & training on the skill to participate inside the teaching hall & 3.26 & .92 & High \\
8 & 13 & The skill of preparing research & 3.23 & .99 & High \\
9 & 8 & Identify the laws and regulations of the university & 3.16 & 1.04 & High \\
10 & 15 & Training to prepare reports & 3.14 & .96 & High \\
11 & 7 & To identify the mechanism of registration materials & 3.13 & .95 & High \\
11 & 10 & Knowledge of the requirements of each major & 3.13 & 1.10 & High \\
13 & 12 & The skill to identify the teaching plan & 3.05 & 1.05 & High \\
14 & 11 & the skill of recording important notes & 3.03 & 1.06 & High \\
15 & 9 & Knowledge of undergraduate majors & 2.95 & 1.12 & Medium \\
& & Academic skills & 3.22 & .79 & High \\
\hline
\end{tabular}

Table (8) shows that the means have ranged from (2.95- 3.56), where item No. 1 , which is "to practice reading skills" came in the first place and an arithmetic mean was (3.56), while item (9) which is "knowing undergraduate majors' came at the final rank and an arithmetic mean of (2.95). The arithmetic mean of the academic skills as a whole reached (3.22).

Second question: Are there differences in the levels of necessary transitional skills for the acoustically disabled to transfer from school to the university from the standpoint of hearing impaired at public and private universities due to gender?

To answer this question arithmetic means and standard deviations of the transitional skills provided for the hearing-impaired due to gender variable, and to indicate the statistical differences between the arithmetic means " $\mathrm{T}$ " test was used, and the tables below No. (9) Illustrates this.

Table 9. Means and Standard Deviations and "T" Test for the Effect of Transitional Skills Provided for the Hearing Impaired

\begin{tabular}{lllllllc}
\hline & Gender & $\mathrm{N}$ & Mean & $\begin{array}{l}\text { Standard } \\
\text { deviation }\end{array}$ & $\begin{array}{l}\text { "T" } \\
\text { value }\end{array}$ & Df & Sig \\
\hline Communication skills & Male & 31 & 2.60 & .64 & -3.052 & 78 & .003 \\
& Female & 49 & 3.01 & .54 & & & \\
Social skills & Male & 31 & 2.77 & .60 & -1.026 & 78 & .308 \\
\multirow{2}{*}{ Academic skills } & Female & 49 & 2.90 & .51 & & & \\
\multirow{2}{*}{ Total score } & Male & 31 & 3.14 & .93 & -.679 & 78 & .499 \\
& Female & 49 & 3.26 & .69 & & & \\
& Male & 31 & 2.85 & .61 & -1.789 & 78 & .078 \\
& Female & 49 & 3.06 & .43 & & & \\
\hline
\end{tabular}


Seen from the table (9) the existence of statistically significant differences $(\alpha=0.05)$ due to the effect of gender on communication skills, and the differences were in favor of females. While there were no statistically significant differences in the rest of the skills in the total score.

Third question: Are there differences in the levels of transitional skills necessary for the acoustically disabled to transfer from school to the university from the viewpoint of hearing impaired at public and private universities due to the student's major?

To answer this question means and standard deviations was extracted for the transitional skills provided for the acoustically disabled due to specialty variable, and to indicate the statistical differences between the arithmetic means " $\mathrm{T}$ " test was used, and the table below illustrates this.

Table 10. Means and Standard Deviations and "T" Test of the Impact of Specialization on Transitional Skills Provided for the Hearing Impaired

\begin{tabular}{|c|c|c|c|c|c|c|c|}
\hline & Specialization & $\mathrm{N}$ & Mean & $\begin{array}{l}\text { Standard } \\
\text { deviation }\end{array}$ & $\begin{array}{l}\mathrm{T} \\
\text { value }\end{array}$ & Df & Sig \\
\hline \multirow[t]{2}{*}{$\begin{array}{l}\text { Communication } \\
\text { skills }\end{array}$} & $\begin{array}{l}\text { Humanitarian } \\
\text { colleges }\end{array}$ & 70 & 2.92 & .57 & 2.641 & 78 & .010 \\
\hline & $\begin{array}{l}\text { Scientific } \\
\text { colleges }\end{array}$ & 10 & 2.39 & .74 & & & \\
\hline \multirow[t]{2}{*}{ Social skills } & $\begin{array}{l}\text { Humanitarian } \\
\text { colleges }\end{array}$ & 70 & 2.91 & .47 & 2.572 & 78 & .012 \\
\hline & $\begin{array}{l}\text { Scientific } \\
\text { colleges }\end{array}$ & 10 & 2.45 & .84 & & & \\
\hline \multirow[t]{2}{*}{ Academic skills } & $\begin{array}{l}\text { Humanitarian } \\
\text { colleges }\end{array}$ & 70 & 3.25 & .69 & 1.099 & 78 & .275 \\
\hline & $\begin{array}{l}\text { Scientific } \\
\text { colleges }\end{array}$ & 10 & 2.96 & 1.28 & & & \\
\hline \multirow[t]{2}{*}{ Total score } & $\begin{array}{l}\text { Humanitarian } \\
\text { colleges }\end{array}$ & 70 & 3.03 & .42 & 2.497 & 78 & .015 \\
\hline & $\begin{array}{l}\text { Scientific } \\
\text { colleges }\end{array}$ & 10 & 2.61 & .91 & & & \\
\hline
\end{tabular}

Seen from the table (10) the existence of statistically significant differences $(\alpha=0.05)$ due to the impact of specialization on all the skills in the total score with the exception of academic skills, the differences were in favor of humanity colleges.

Fourth question: Are there differences in the levels of necessary transitional skills for the acoustically disabled for the transition from school to the university from the viewpoint of hearing impaired at public and private universities due to the years of enrollment in the university? 


\section{Macrothink}

International Journal of Education

ISSN 1948-5476

2017, Vol. 9, No. 1

To answer this question arithmetic means and standard deviations for the transitional skills due to year enrollment variable were extracted, and table (11) below shows that.

Table 11. Means and Standard Deviations for the Transition of Skills Provided for the Hearing Impaired Due to Variable Year Enrollment Variable

\begin{tabular}{lllll}
\hline & Categories & N & Mean & $\begin{array}{l}\text { Standard } \\
\text { deviation }\end{array}$ \\
\hline Communication skills & 1st year & 30 & 2.84 & .71 \\
& 2nd year & 22 & 2.73 & .53 \\
& 3rd year & 17 & 3.02 & .35 \\
& 4th year & 11 & 2.87 & .80 \\
Total & 80 & 2.85 & .61 \\
Social skills & 1st year & 30 & 2.77 & .64 \\
& 2nd year & 22 & 2.75 & .32 \\
Academic skills & 3rd year & 17 & 3.05 & .27 \\
& 4th year & 11 & 2.98 & .84 \\
& Total & 80 & 2.85 & .55 \\
& 1st year & 30 & 2.96 & .75 \\
2nd year & 22 & 3.41 & .68 \\
Total score & 3rd year & 17 & 3.39 & .63 \\
& 4th year & 11 & 3.25 & 1.15 \\
& Total & 80 & 3.22 & .79 \\
& 1st year & 30 & 2.85 & .54 \\
2nd year & 22 & 2.97 & .31 \\
3rd year & 17 & 3.16 & .36 \\
& 4th year & 11 & 3.04 & .85 \\
Total & 80 & 2.98 & .52 \\
\hline
\end{tabular}

Table 11 shows the surface variation in means and standard deviations for the transition skills provided for the acoustically disabled because of the different categories of year enrollment variable, and to denote the statistical differences between the means one-way analysis of variance have been used as in table (12).

Seen from the table (12) that there were no statistically significant differences at the significance level $(\alpha=0.05)$ due to the years of enrollment in all the skills in the total score. 
Table 12. One-Way Analysis of Variance of the Impact of Years of Enrollment on Transitional Skills Provided for the Hearing Impaired

\begin{tabular}{lllllll}
\hline & Source & $\begin{array}{l}\text { Sum of } \\
\text { squares }\end{array}$ & df & Mean & $\begin{array}{l}\text { Calculated } \\
\text { F }\end{array}$ & Sig \\
\hline Communication & Between groups & .787 & 3 & .262 & .697 & $\mathbf{. 5 5 7}$ \\
skills & Within groups & 28.618 & 76 & .377 & & \\
Social skills & Total & 29.406 & 79 & & & \\
& Between groups & 1.309 & 3 & .436 & 1.495 & $\mathbf{. 2 2 3}$ \\
& Within groups & 22.179 & 76 & .292 & & \\
Academic skills & Total & 23.488 & 79 & & & \\
& Between groups & 3.209 & 3 & 1.070 & 1.786 & $\mathbf{. 1 5 7}$ \\
& Within groups & 45.529 & 76 & .599 & & \\
& Total & 48.738 & 79 & & & \\
& Between groups & 1.041 & 3 & .347 & 1.324 & $\mathbf{. 2 7 3}$ \\
& Within groups & 19.926 & 76 & .262 & & \\
\hline & Total & $\mathbf{2 0 . 9 6 7}$ & $\mathbf{7 9}$ & & & \\
\hline
\end{tabular}

\section{Discussion of the Results}

The findings of the first question: What are the transitional skills required for the transition from school to the university from the viewpoint of hearing impaired at public and private universities in Jordan transitional skill? The academic skills ranked first with the highest arithmetic mean which was (3.22), followed in the second place by both communication skills and social skills with a mean of (2.85), and the arithmetic mean of the total score reached (2.98). This is consistent with the study of Masadeh (1990) entitled disabled students' problems in Jordanian universities where the study aimed to identify these problems and its relationship to gender and academic level and the type of disability and place of residence, type of college, where the study results show a number problems faced by the acoustically disabled at universities in Jordan, including academic problems, which have been summarized in academic skills dimension, and that means that the acoustically disabled students must be provided with the necessary academic skills that will help them make the transition from school to university and adaptation with university atmosphere, so the student with acoustical disability is not exposed to academic problems due to lack of the necessary academic preparedness, where the failure to provide acoustically disabled with these skills lead to assess the capabilities of the acoustically disabled negatively and this is reflected on the self-esteem and performance in general.

Results related to the second question: Are there differences in the necessary transitional skills levels for the acoustically disabled for the transition from school to the university from the viewpoint of hearing impaired at public and private universities due to gender?

The results showed no statistically significant differences $(\alpha=0.05)$ due to the effect of gender in communication skills and the differences were in favor of females, while it did not show statistically significant differences in the rest of the skills in the total score. This is 
consistent with a study conducted by MarsChark (2005) entitled access to education beyond high school through the translation of sign language, where the goal of this study is to identify the effectiveness of translation in sign language for the deaf in the classroom, where the results indicated that there is a contradiction with respect the importance of students' preference to translate, and pointed out that the deaf students acquire information less than their colleagues who heard, and they are weak in school readiness, quality of education and the quality of translation, which demonstrates the need of acoustically disabled males and females to practice communication skills in order to supply with information from listeners and improve academic level.

This is consistent with (Lukomski, 2007) study which aimed to recognize the differences in the view of deaf students and listeners to their psychological and social agreement after they move to the university stage, where it was found that the deaf classified themselves as having difficulties in social life more than listeners also they have less capacity to deal with the problems, and the results showed that deaf females have more anxiety. This explains the need for acoustic disabled to communication skills more than males as females psychologically to have a tendency to communicate and interact with others more than males, as the lack of communication skills afforded to injury emotional troubles such as anxiety. This is contrary to the study of Masaadeh (1990), entitled "Problems of students with disabilities in Jordanian universities" where the study aimed to identify these problems and their relationship to gender and academic level and the type of disability and place of residence, type of college, where the researcher found the lack of impact of the gender variable, as the problems of the hearing impaired, whether males or females in university life are approximately similar.

Results relating to the third question: Are there differences in the levels of necessary transitional skills for the acoustically disabled for the transition from school to the university from the viewpoint of hearing impaired at public and private universities due to student's specialization? showed the existence of statistically significant differences $(\alpha=0.05)$ due to the impact of specialization in all the skills in the total score with the exception of academic skills, and the differences were in favor of the Humanitarian colleges. this does not agree with the study of Massadeh (1990) study entitled " Problems of disabled students in Jordanian universities" where the study aimed to recognize these problems and their relationship to gender and academic level and the type of disability and place of residence and type of college, where results showed a lack of effect of specialization variable or college on the existence of problems among students with acoustic disabilities, since the hearing-impaired, mostly head to the humanitarian faculties and in this study, the sample was mostly from humanitarian colleges where the number was 70 students, while the science faculties 10 students, where the scientific disciplines require high rates and this line with personal characteristics enjoyed by acoustic disabled students in terms of capacity to manage the needs of students with acoustically disabilities compared with humanitarian disciplines and this may explain the need of students with acoustic disabilities in the humanitarian colleges to transition skills necessary for the transition from school to university.

As shown in the results related to the fourth question: Are there differences in the levels of transitional skills necessary for the acoustically disabled for the transition from school to the 
university from the viewpoint of hearing impaired at public and private universities due to years of enrollment in the university? Results showed that there are no statistically significant differences at the significance level $(\alpha=0.05)$ due to the years of enrollment in all the skills in the total score. this consistent with the study of (Gale, 2006) in the United States aimed to identify the learning needs of students with audio disabilities to quality standards, where the study sample consisted of 56 male and female students with hearing disabilities in one of New York University, the researcher used a questionnaire about the effectiveness of services provided, where the results showed that the students state in writing is in the evolutionary levels. Reason for the lack of evolution in the skills of students in the university stages may be a lack of understanding of teachers' general characteristics for the hearing impaired, and compared their abilities capabilities with listeners' students.

\section{Recommendations}

- Further studies are needed on the transitional skills for acoustically debilitated to move into married life, teenage,,,,

- Conducting studies on the effectiveness of communication skills used by the hearing-impaired.

- Conducting studies on the efficiency of sign language interpreters.

- Preparation of the courses for teachers and students to learn about the characteristics and capabilities of hearing-impaired.

- Make adjustments to the university tests commensurate with the hearing-impaired, such as paragraphs, the time available,,,

- Prepare a study plan commensurate with the capabilities of audio disabled where the nature of the courses contained in the study plan.

\section{References}

Al Khatib, J. M. (2007). A survey of general education teachers' knowledge of learning disabilities in Jordan. International Journal of Special Education, 22(1), 72-76.

Bochner, J. H., \& Walter, G. G. (2005) Evaluating deaf students' readiness to meet the English language and literacy demands of postsecondary educational programs. Journal of Deaf Studies and Deaf Education, 10, 232-243. https://doi.org/10.1093/deafed/eni025

Gale Encyclopedia of Neurological Disorders (2006). Learning Needs of Deaf in the Institutions. American Annuals of Deaf Students, 14(3) 90-164.

Heward,W. L. (2006). Exceptional Children: An introduction to special education ( $8^{\text {th }}$ Ed.). Upper Saddle River, NJ: Pearson Education, Inc. 
Khatib et al. (2007). Introduction to teach students with special needs. Amman: Dar Al Fikr.

Qaryouti, Sartawi, Smadi. (1995). Introduction to special education. Dubai: Dar Al Kalum for publishing and distribution.

Kuder, S (2003). Teaching Students with Language and Communication Disabilities (2 ${ }^{\text {nd }}$ ed.). US, Boston: Allyn and Bacon publications

Lukomski, J. (2007). Deaf College Students, Perceptions of their social emotional adjustment. Journal of Deaf Studies and Deaf Education, 12(4), 486-494. https://doi.org/10.1093/deafed/enm008

Marschark, M., Sapere, C., \& Seewagen, R. (2005). Access to Postsecondary through Sing Language Interpreting. Journal of Deaf, 10, 38-50.

Masaadeh, A. (1990). Problems of disabled students at Jordanian universities problem, Unpublished MA Thesis, College of Education, Yarmouk University, Jordan.

Sitlington, P., \& Clark, G. (2006). Transition Education and Services for Student with Disabilities. Boston: Ally \& Bacon.

Smith, T. B., Dean, B., Floyd, S., Silba, C., Yamashita, M., Durtschi, J., et al. (2007). Pressing issues in college counseling. A survey of American college counseling association members. Journal of College Counseling, 10, 64-78. https://doi.org/10.1002/j.2161-1882.2007.tb00007.x

\section{Copyright Disclaimer}

Copyright for this article is retained by the author(s), with first publication rights granted to the journal.

This is an open-access article distributed under the terms and conditions of the Creative Commons Attribution license (http://creativecommons.org/licenses/by/3.0/). 